\title{
Spondylolysis in fast bowlers: principles of prevention and a survey of awareness among cricket coaches
}

\author{
Philip A Bell MB ChB, Dip Sports Med \\ Sports and Fitness Assessment, London Bridge Clinic, London, UK
}

\begin{abstract}
Back injury in general, and spondylolysis in particular, represents a serious threat to the fast bowler. Hereditary factors, poor technique, overuse, and poor preparation for fast bowling may combine to produce the 'at risk' bowler. Three first-class county coaches were interviewed to establish a level of awareness of the lesion, with an emphasis on preparation of fast bowlers and the roles of technique alteration and bowling prescription in reducing the risk of back injury.
\end{abstract}

Keywords: Cricket, fast bowler, spondylolysis, prevention, awareness

Fast bowlers have proved the most potent weapon at test match level in the last two decades. Fast bowling is an explosive action. Concern has been expressed at the epidemic of back injuries among fast bowlers at élite and club level ${ }^{1}$. Fitch ${ }^{2}$ describes fast bowling as one of the most injury-liable non-contact activities.

Back injury, whether of bone, intervertebral disc, apophyseal joint, or soft tissue is common among fast bowlers. More specifically, spondylolysis, a stress fracture occurring at the pars interarticularis, the vulnerable pivot between the vertebral body and the posterior apophyseal joints, represents a serious threat to their careers.

During the $1986-1987$ season, $38 \%$ of 82 élite young Western Australian fast bowlers developed a significant back injury (requiring an absence of at least one game $)^{1}$. Nine $(11 \%)$ developed stress fractures of the pars - one at L4, seven at L5, and one at an incompletely sacralized S1.

Hereditary factors, incorrect bowling technique, poor preparation and overuse (repetitive stress) all have a part to play and will be discussed in turn.

A knowledge of these factors forms the basis of any prevention programme. It is important that coaches and team physiotherapists are aware of the lesion to ensure prompt diagnosis and appropriate management by team physicians. Early diagnosis of a stress reaction in the pars may prevent progression to spondylolysis or spondylolisthesis.

Address for correspondence: Dr P. A. Bell, Sports and Fitness Assessment, London Bridge Clinic, 1 St. Thomas Street, London SE1 9RY, UK

(C) 1992 Butterworth-Heinemann Ltd 0306-3674/92/040273-03

\section{Hereditary and associated factors}

Spondylolysis is virtually unknown at birth, unusual under 5 years of age, and rises thereafter to level out after the age of 20 years ${ }^{3}$. The incidence in the general population is approximately $5 \%$. Among sportsmen, particularly those participating in sports involving repetitive flexion, rotation and hyperextension of the lumbar spine, it is much more common ${ }^{4}$. It is less common in blacks (American blacks $2 \%)^{5}$. Wiltse ${ }^{6,7}$ has demonstrated a familial incidence of $31 \%$ on radiographic screening of families in which one member has a spondylolisthesis. Racial differences may confer a relative immunity among West Indian fast bowlers.

Spina bifida is an important associated anomaly and transitional vertebrae seem to be protected from defects ${ }^{8}$.

\section{Incorrect technique}

There are three main fast bowling techniques:

1. side-on action;

2. front-on action;

3. mixed action.

A mixed bowling action is a combination of the side- and front-on styles. The bowler is front-on at back foot impact (BFI) but, in an attempt to obtain a more side-on alignment, counter-rotates the shoulders to decrease shoulder alignment at front foot impact (FFI) ${ }^{9}$. This results in a hyperextended and laterally flexed spine. Excessive shoulder rotation, or partial closure, of $>40^{\circ}$ to attain a more side-on shoulder alignment is significantly associated with spondylolysis and soft tissue injury to the back.

There are arguments for continuing to encourage a side-on action as the MCC coaching manual has done for many years. Not only does it allow consistent away swing but the additional rotational movement may allow more effective force summation ${ }^{10}$.

Whatever the merits of the front- and side-on bowling action, evidence is emerging that the mixed bowling action may be associated with spondylolysis and should be discouraged as early as possible in the fast bowler's career. 


\section{Poor preparation}

Although power, flexibility, and sufficient aerobic and anaerobic capacity to sustain speed and direction are essential to the fast bowler, it is important to emphasize the principle of the specificity of training. There is evidence from this survey to suggest that the modern-day fast bowler bowls less in training than the fast bowlers of old. Observing the principles of progression and overload, the bowler must bowl enough in training to prevent stress injury and breakdown in match play.

\section{Overuse}

The neural arch, in the region of the pars interarticularis, is vulnerable when repetitive stresses act upon $i^{11}$. There is evidence of fatigue failure as the primary mechanism ${ }^{3}$.

In the young sportsman, the disc is relatively elastic and forces are more readily transmitted to the facet joints. Complete ossification of the neural arch may not have occurred and growth cartilage is less resistant to repetitive stress than adult cartilage ${ }^{11}$.

The Australian cricket board emphasizes the hazards of bowling too fast, for too long, during practice and match play. Back injury may be related to the repetitive stress of bowling too many overs in any single spell and/or bowling too many spells.

A sudden increase in bowling intensity associated with match play may be particularly relevant. There appears to be a need to limit excessively long bowling spells, particularly during the developmental phase of growth, and to allow sufficient rest and recovery time.

\section{Clinical features}

The condition in athletes usually presents with mechanical low back pain ${ }^{12}$. Crescendo-type pain is typical, occurring initially after bowling, then earlier and earlier during a spell until the bowler is unable to bowl at all.

Clinical suspicion should be high as the signs may be subtle. Spondylolysis may only be picked up by the one-legged hyperextension test ${ }^{13}$. Associated disc degeneration is recognized and signs of an associated disc prolapse should be sought $t^{14}$.

Right-handed bowlers tend to develop spondylolysis in the left pars, the side associated with rotation and extension of the back. Right-sided defects associated with compression forces may also occur. The L5 level is most commonly affected.

Appropriate investigation to exclude spondylolysis is essential and may include plain radiographs, including oblique views, technetium bone scan and computerized tomography ${ }^{2,15,16}$.

Athletes may continue to train in spite of low back pain and Jackson ${ }^{17}$ emphasizes the dangers of ignoring it. Three of Wiltse's gymnasts, with negative initial radiographic examination for low back pain, continued to train and went on to develop pars defects, two with a $25 \%$ spondylolisthesis.

\section{Survey of awareness}

Three coaches were interviewed personally. Two were head coaches of first-class county sides, both of which have been county champions within the last 5 years. One had played as an all-rounder for England, the other in county second XI cricket. The third, an ex-county fast bowler, was involved in school, club and county young cricketers' coaching. All were aged between 55 and 60 years.

All were aware of the propensity of fast bowlers to back problems, although only two were specifically aware of stress fractures of the lumbar spine. Only one felt back injury was common among young cricketers under his wing, and none felt that back injury accounted for a significant drop-out rate. However, all agreed that back injury now appears more common in the professional game than it was, and that the modern-day fast bowler is more front-on. Two coaches added that there were far fewer genuine swing bowlers around today and this was partly due to the bowling style adopted by modern-day fast bowlers.

Training programmes for fast bowlers were poorly defined and structured. There were no specific exercise regimens in flexibility, strength, speed and endurance. There was no individual exercise prescription or home exercise regimens.

The use of bowling prescription was limited. One coach restricted net sessions to $45 \mathrm{~min}$ of bowling and another limited his young fast bowlers to five-over spells.

Technique alteration was used by all three coaches, but not in an attempt to reduce injury risk. One actively encouraged a side-on technique for its other virtues. One stressed the importance of catching them young.

No formal technique analysis, e.g. video films, or review was undertaken, although the coaches felt this was being monitored continuously by themselves.

\section{Discussion}

It is important that cricket coaches develop an awareness of the condition of spondylolysis and its incidence in the fast bowling population. They should be familiar with the roles of poor preparation, incorrect technique, and overuse in its aetiology.

Continuous cricket, commercial pressures, the one-day game, and contractual arrangements can make it difficult for coaches to prepare their fast bowlers adequately.

Sports physiologists are aware of the specificity of training with, for example, rowers training by rowing and runners by running. All the coaches interviewed agreed that fast bowlers used to bowl more in the nets. One described pre-season training of old as 'plenty of running, three net sessions a day, with a bat every other Friday!'. Another coach admitted to the difficulty he had in getting his players to net. It is clear that a fast bowler, unprepared for the sudden increase in bowling intensity that accompanies the beginning of the season proper, or a return from injury, is at risk of stress fracture. 
Coaches must encourage correct technique from an early age and supervise some form of bowling prescription.

The appliance of science to élite cricket in this country has been slow and it is interesting to contrast the 20-week pre-season training programme of the Western Australian squad with that of the average first-class county in this country.

In Victoria and New South Wales, élite young fast bowlers are progressively monitored to identify 'at risk' bowlers $^{18}$. Initial screening showed a significant percentage with past or present symptoms of lumbar spine injury. Appropriate treatment, exercise regimens, and desired workload can then be prescribed.

The days when you could whistle at the top of a Yorkshire pit and a fast bowler would appear are long gone. The application of correct technique and training principles may not only help to produce more fast bowlers but prevent their premature demise.

There appears to be a degree of awareness among county coaches of back injury in general, and spondylolysis in particular. However, the size of the problem seems to be underestimated and the aetiological roles of incorrect technique, poor preparation and overuse are poorly understood. Correspondingly, technique alteration, training programmes, and bowling prescription appear unstandardized and unscientific. A strong argument for technique alteration, to avoid the potentially dangerous mixed bowling action, can be made. The earlier in the young fast bowler's career this can be done the better, with screening both to prevent and detect the development of back injury. There is no evidence to suggest an advantage of the front-on over the side-on bowling action. It is probable that the classical side-on technique is a more efficient and safer way to bowl and the MCC coaching manual should continue to encourage it.

\section{References}

1 Foster DH, John D, Elliot B, Ackland T, Fitch K. Back injuries to fast bowlers in cricket: a prospective study. $\mathrm{Br} J$ Sports Med 1989; 23: 150-4.

2 Fitch K. Spondylolysis in fast bowlers - induced by heredity or stress. Australian Sports Medicine Federation, National Scientific Conference, Adelaide, 1987; Abstract 32).

3 Wiltse LL, Widell EH, Jackson DW. Fatigue fracture: the basic lesion in isthmic spondylolisthesis. J Bone Joint Surg [Am] 1975; 57-A: 17-22.

4 Hoshina H. (1980) Spondylolysis in athletes. Phys Sports Med 1980; 8: 75-9.

5 Roche MB, Rowe GG. Incidence of separate neural arch and coincident bone variations. J Bone Joint Surg [Am] 1952; 34-A: 491-94.

6 Wiltse LL. Spondylolisthesis in children. Clin Orthop 1961; 21: 156-63.

7 Wiltse LL. The aetiology of spondylolisthesis. J Bone Joint Surg [Am] 1962; 44-A: 539-60.

8 Eisenstein S. Spondylolysis. A skeletal investigation of two population groups. J Bone Joint Surg [Br] 1978; 60-B: 488-94.

9 Elliot BC, Foster DH, Gray S. Biomechanical and physical factors influencing fast bowling. Aust J Sci Med Sport 1986; 18: 16-21.

10 Elliot BC, Foster DH. A biomechanical analysis of the front-on and side-on fast bowling techniques. I Human Movement Studies 1984; 10: 83-94.

11 Cyron BM, Hutton WC. The fatigue strength of the lumbar neural arch in spondylolysis. J Bone Joint Surg [Br] 1978; 60-B: 234-8.

12 Turner RH, Bianco RJ. Spondylolysis and spondylolisthesis in children and teenagers. I Bone Joint Surg [Am] 1971; 53-A: 1298-306.

13 Blackburne JS. Spondylolisthesis in sportsmen. J R Coll Surg Edinb 1989; 34: 512-14.

14 Corrigan AB. Cricket injuries. Aust Family Physician 1984; 13 : 558-62.

15 Billings RA, Burry HC, Jones R. Low back injury in sport. Rheumatol Rehabil 1977; 16: 236-9.

16 Rothman SLG. Computed tomography of the spine in older children and teenagers. Clin Sports Med 1986; April: 247-70.

17 Jackson DW, Leon MD, Wiltse MD, Cirincione RJ. Spondylolysis in the female gymnast. Clin Orthop Rel Res 1976; 117: 68-73.

18 Keech MK, MacKay G. Lumbosacral screening and prevention programme for junior elite male fast bowlers. Aust I Sci Med Sport 1988; December: 22. 